\title{
Clinical autonomic research: carrying on the torch
}

\section{Message from the Editors}

\author{
Jens Jordan • Horacio Kaufmann
}

Published online: 4 April 2014

(C) Springer-Verlag Berlin Heidelberg 2014

Dear Readers,

More than twenty years ago, in 1991, the first issue of Clinical Autonomic Research appeared in print. Since then, Christopher J. Mathias served as Editor-in-Chief. He had a pivotal role in initiating and shaping the Journal and in navigating it through difficult times. Ronald Polinsky joined him as Co-Editor in 1994 up until 1999 when Horacio Kaufmann assumed the Co-Editor role committing time and energy to ensure the success of the Journal. The Editors' efforts were supported by a highly motivated team of associate editors, editorial board members, editorial staff, and countless reviewers. Over the years, the Journal has gone through changes in publishers, and has now been with Springer for the last decade.

Today, Clinical Autonomic Research is an internationally recognized interdisciplinary Journal covering a wide range of organ systems and clinical disciplines. Autonomic scientists continue to submit excellent work. The Journal has a truly translational approach, publishing original contributions and reviews on basic as well as clinical research. Together with the technical methodological innovations provided, the research contributes to the better understanding of human autonomic physiology and pathophysiology. Thus, Clinical Autonomic Research became what Professor Mathias envisioned in his first editorial contribution [1]. Meanwhile, Clinical Autonomic Research is endorsed by the American Autonomic Society and by the European Federation of Autonomic Societies (EFAS).

Clinical Autonomic Research past Associate Editors included Murray Esler, Ian Macdonald, Ronald Polinsky, and Eduardo Benarroch. Currently, Wouter Wieling, Ronald Schondorf, Vaughan Macefield, and David Goldstein serve as Associate Editors.

For Clinical Autonomic Research this is an important year. Christopher Mathias stepped down as Co-Editor. Handing the Journal to his successors in a good shape. Dr. Jens Jordan will take over to serve as Co-Editor-in-Chief along side Horacio Kaufmann.

Owing to its name the Journal will continue to provide a platform for research aimed at improving the understanding and treatment of human autonomic disorders. Indeed, there is renewed interest in this research in the general medical community as new treatments targeting the autonomic nervous system, such as renal nerve ablation of electrical carotid sinus stimulation in the treatment of hypertension, enter clinical practice. Therefore, we hope to attract a wider readership in years to come. In the last decades, there has been much progress in methodologies to better diagnose autonomic disorders. Moreover, symptomatic treatments have been discovered and refined. These issues are covered by numerous publications, which appeared in Clinical Autonomic

J. Jordan

Hannover Medical School, Hannover, Germany

H. Kaufmann ( $\square)$

NYU Dysautonomia Center, New York, USA

e-mail: clinicalautonomicresearch@gmail.com 
Research over the years. However, causative treatments remain scarce. Therefore, as we lead the Journal forward, we will broaden the scope to attract more publications that could subsequently lead to targeted treatments of autonomic disorders. Finally, the editorial team will continue the efforts to improve the efficiency and effectiveness of manuscript reviews.

Sincerely,

Jens Jordan, MD

Editor-in-Chief

Horacio Kaufmann, MD

Editor-in-Chief

\section{References}

1. Mathias CJ (1991) Clinical autonomic research in the 1990s. Clin Auton Res 1:3 